Case Report

\title{
Rare Contents of an Internal Hernia through a Defect of the Broad Ligament of the Uterus
}

\author{
Masafumi Takahashi $(\mathbb{D}$, Masanori Yoshimitsu (D), Takuya Yano $(\mathbb{D})$, Hitoshi Idani, \\ Shigehiro Shiozaki, and Masazumi Okajima \\ Department of Surgery, Hiroshima City Hiroshima Citizens Hospital, 7-33, Motomachi, Naka-ku, Hiroshima City, Hiroshima, Japan \\ 730-8518 \\ Correspondence should be addressed to Masanori Yoshimitsu; myoshimitsu1970@gmail.com
}

Received 23 February 2021; Accepted 23 May 2021; Published 30 May 2021

Academic Editor: Muthukumaran Rangarajan

Copyright (c) 2021 Masafumi Takahashi et al. This is an open access article distributed under the Creative Commons Attribution License, which permits unrestricted use, distribution, and reproduction in any medium, provided the original work is properly cited.

\begin{abstract}
Herniation through a defect of the uterine broad ligament is a rare internal hernia that is difficult to diagnose definitively. Common hernia contents contain ileal loops. Herein, we report a rare case of internal herniation of both the ileum and fallopian tube through a defect of the broad ligament. A 52-year-old woman presented to our hospital with suprapubic pain and vomiting. She had a history of bowel obstruction following cesarean section. On abdominopelvic computed tomography, we suspected a closed-loop obstruction associated with bowel herniation in the right broad ligament. However, we could not identify an area of poor enhancement adjacent to distended small intestines. Emergency laparoscopic exploration revealed a viable ileal loop and incarcerated organ. Therefore, we switched to laparotomy that revealed the right fallopian tube as the ischemic organ. We reduced the hernia, resected necrotic right fallopian tube, and closed the defect of the broad ligament. The patient had an uneventful postoperative course. Rare hernia contents might complicate preoperative clinical diagnosis. Laparoscopy is useful for establishing a definitive diagnosis and treating broad ligament hernias.
\end{abstract}

\section{Introduction}

Internal hernias are rare causes of bowel obstruction, and internal herniation through a defect of the broad ligament of the uterus is even rarer, accounting for $4 \%-5 \%$ of all internal hernias [1]. Hernia contents usually include the ileum. In addition, several studies have reported constriction of organs such as the colon and fallopian tube in patients with internal hernia $[2,3]$. We have recently encountered a rare case of broad ligament hernia incarcerating not only the ileum but also the fallopian tube in a middle-aged female patient. We suggest that this case might have clinical implications in the diagnosis and treatment of internal hernias.

\section{Case Presentation}

A 52-year-old woman presented to our hospital with lower abdominal pain and vomiting that started 6 hours prior to presentation. Her past medical history was significant for bowel obstruction following cesarean section. She denied having any fever or chills. There was no rebound tenderness or abdominal guarding.

Laboratory test results showed an elevated white blood cell count $\left(11,000 / \mathrm{mm}^{3}\right)$. Contrast-enhanced abdominopelvic computed tomography (CT) showed a distended, fluidfilled closed loop with mesenteric fat haziness at the right side of the uterus, which was deviated to the left. The bowel wall enhancement was normal. However, there was a spheroidal area of poor enhancement adjacent to the distended small intestines, assuming it was the right ovary or ascites (Figure 1).

Following the diagnosis of a closed-loop obstruction associated with bowel herniation in the right broad ligament of the uterus, emergency surgery was performed. Laparoscopic exploration revealed a viable ileal loop and an organ suspected to be ischemic (Figure 2). We then switched to 


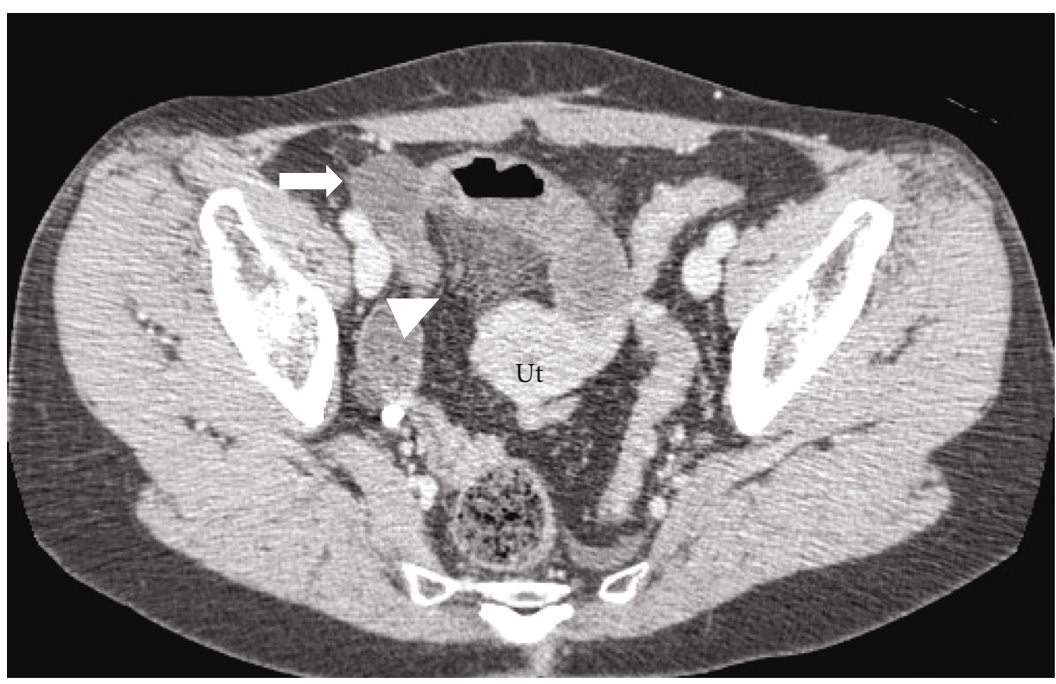

FIGURE 1: Contrast-enhanced computed tomography (CT) findings. The mesentery converges at the right side of the uterus (arrowhead). The uterus is deviated to the left. There is a spheroidal area of poor enhancement (arrow). Ut: uterus.

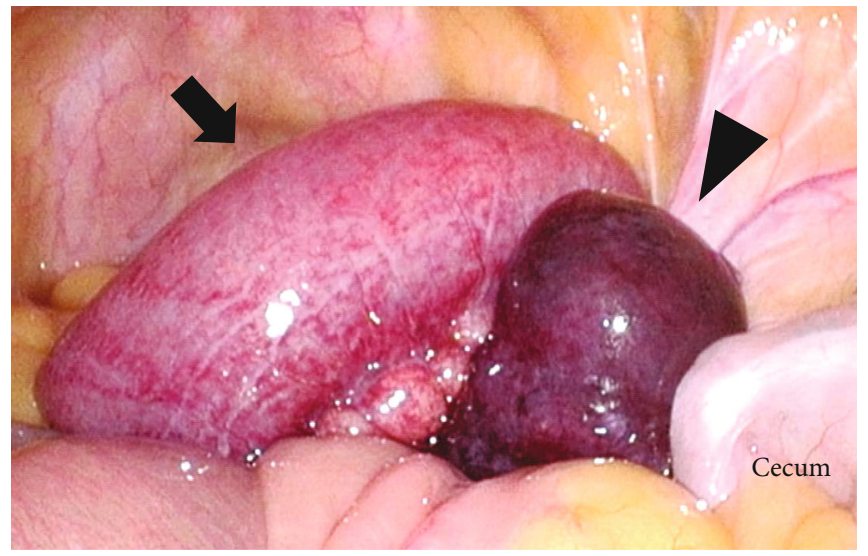

FIGURE 2: Surgical findings (laparoscopy). Within the pelvis, a viable ileal loop (arrow) and a necrotic organ are shown, suspecting it as a result of ischemia (arrowhead).

laparotomy to enable examining this incarcerated organ. Laparotomy showed that incarceration was caused by herniation through the right broad ligament of the uterus in a posterior-to-anterior direction (Figure 3). The length of strangulated ileal loop was approximately $30 \mathrm{~cm}$, which was preserved and had no ischemic changes. The organ with suspected ischemia was the enlarged ampullary portion of the right fallopian tube, which was incarcerated and gangrenous. We reduced the hernia and performed a right salpingectomy. The hernial orifice diameter was $3.0 \mathrm{~cm}$, and the defect was closed with a continuous suture. The patient had a favorable postoperative course and was discharged to home on postoperative day 8 .

\section{Discussion}

Internal herniation through a defect in the uterine broad ligament is extremely rare. Broad ligament defects may be congenital or acquired [4]. Congenital defects arise from

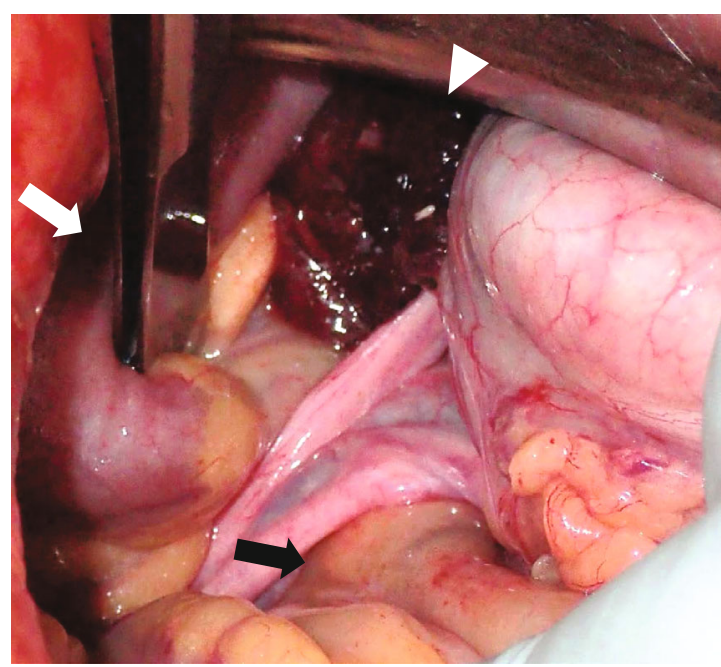

FIgURE 3: Surgical findings (laparotomy). The ileal loop (white arrow) and right fallopian tube (white arrowhead) are incarcerated, and the hernial orifice is a defect in the right broad ligament (black arrow). 
TABLE 1: Review of recent studies reporting broad ligament hernia.

\begin{tabular}{|c|c|c|c|c|c|}
\hline & Authors [ref. no.] & $\begin{array}{c}\text { History of } \\
\text { surgery/parturitions }\end{array}$ & Approach & Procedure for orifice & Contents \\
\hline 1 & Khetan et al. [7] & None & $\mathrm{L}$ & Closure & Small bowel \\
\hline 2 & Takeyama et al. [8] & Two parturitions & SILS & Closure & Sigmoid colon \\
\hline 3 & Toolabi et al. [9] & None & $\mathrm{L}$ & Closure & Small bowel \\
\hline 4 & Park et al. [10] & Uterine myomectomy & $\mathrm{L}$ & Closure & Small bowel \\
\hline 5 & Diémé et al. [11] & Three parturitions & $\mathrm{L}$ & Closure & Small bowel \\
\hline 6 & Rajasekharan et al. [12] & Cesarean section & $\mathrm{O}$ & Closure & Small bowel \\
\hline 7 & Zemour et al. [13] & Small bowel surgery & $\mathrm{O}$ & Closure & Small bowel \\
\hline 8 & Fernandes et al. [14] & None & $\mathrm{O}$ & Closure & Small bowel \\
\hline 9 & Fernandes et al. & None & $\mathrm{O}$ & Closure & Small bowel \\
\hline 10 & Fernandes et al. & None & $\mathrm{O}$ & Closure & Small bowel \\
\hline 11 & Reyes et al. [15] & Sleeve gastrectomy & $\mathrm{O}$ & $\begin{array}{l}\text { Opening and } \\
\text { salpingectomy }\end{array}$ & Small bowel \\
\hline 12 & Koizumi et al. [16] & None & $\mathrm{L}$ & Closure & Small bowel \\
\hline 13 & Sugishita et al. [17] & Right ovarian cyst surgery & $\mathrm{L}$ & Closure & Small bowel \\
\hline 14 & Rohatgi and Joshi [3] & $10^{\text {th }}$-day postcesarean section & $\mathrm{L}$ & $\begin{array}{l}\text { Opening and } \\
\text { salpingectomy }\end{array}$ & $\begin{array}{l}\text { Small bowel and gangrenous } \\
\text { fallopian tube (spontaneously } \\
\text { reduced) }\end{array}$ \\
\hline 15 & Hashimoto et al. [6] & Broad ligament hernia & $\mathrm{O}$ & Closure & Small bowel \\
\hline 16 & Harvitkar et al. [18] & Cesarean section & $\mathrm{L}$ & Closure & Small bowel (spontaneously reduced) \\
\hline 17 & Kaur et al. [19] & Cesarean section & $\mathrm{O}$ & Closure & Small bowel \\
\hline 18 & $\begin{array}{l}\text { Tirado-Peraza et al. } \\
{[20]}\end{array}$ & None & $\mathrm{O}$ & Closure & Small bowel \\
\hline
\end{tabular}

Abbreviations: O: open; L: laparoscopic surgery; SILS: single-incision laparoscopic surgery.

spontaneous rupture of congenital cystic structures within the broad ligament. Acquired defects can be secondary to surgery, pregnancy, delivery trauma, or previous pelvic inflammatory diseases. Congenital defects are usually bilateral, while acquired defects are commonly unilateral. In recent studies, cases without a history of surgery or parturition were not rare. Therefore, evaluation of the bilateral ligaments during surgery is important.

Contents of broad ligament hernias generally include the ileum. However, previous studies have demonstrated that the colon or fallopian tubes can also be incarcerated $[2,3]$. To the best of our knowledge, this is the only case report describing an incarcerated fallopian tube in a broad ligament hernia. In our case, hernia contents included the ampulla part of the right fallopian tube, which was found during surgery.

Early diagnosis of an internal herniation through a defect of the uterine broad ligament is important to enable prompt operative management before ischemic necrosis develops. However, it is generally difficult to diagnose broad ligament hernias due to nonspecific physical symptoms and laboratory tests. Recently, some reports have demonstrated that CT with consistent intravenous contrast is essential for the diagnosis of broad ligament hernias [5]. CT findings include (i) dilated small-bowel loops with air-fluid levels in the Douglas pouch; (ii) distended loops pushing against the uterus, rectum, and sigmoid colon; and (iii) congested mesentery converging at the broad ligament, which is associated with the small bowel loop. In this case, all three characteristics were found. Therefore, we suspected a broad ligament hernia. However, an incarcerated fallopian tube was not identified. On CT scanning, the spheroidal area of poor enhancement that we had assumed to be ascites was an enlarged fallopian tube. Rare herniated contents complicated the diagnosis.

Treatment of a broad ligament hernia is surgery, which should be performed immediately to decrease the duration of incarceration. Necrotic incarcerated organs must be resected. Regarding the orifice, a standard procedure is controversial. Previous studies have proposed the use of nonabsorbable sutures for the closure of a defect or a wide opening with incision of the fallopian tube and round ligament [6]. The latter is a more secure alternative than simple closure when ligaments are congenitally weak. In recent studies, simple closure has been performed more frequently.

The use of laparoscopic surgery for internal hernias, including broad ligament hernias, has increased. CT may suggest a diagnosis of a broad ligament hernia, while laparoscopy could aid in establishing a definitive diagnosis, especially in cases of rare hernial contents. Laparoscopic surgery also allows for treatment following exploration. A switch to laparotomy might be needed when laparoscopic findings suggest signs of necrotic damage to incarcerated organs or limited workspace owing to bowel distension. Establishing a definitive diagnosis with laparoscopy before a laparotomy may allow for a smaller incision. Compared with open surgery, laparoscopic surgery leads to a better postoperative course and a shorter period of hospitalization. Table 1 presents a summary of the results of a literature review since 2018. 


\section{Conclusions}

We suspected a diagnosis of internal herniation through a defect of the uterine broad ligament on preoperative CT, and laparoscopic exploration led to a definitive diagnosis. The rare herniated organs (the ileum and right fallopian tube) complicated the diagnosis.

\section{Data Availability}

The datasets supporting the conclusions are included within this paper.

\section{Conflicts of Interest}

The authors declare that they have no competing interests.

\section{Acknowledgments}

We would like to thank Editage (http://www.editage.com) for English language editing.

\section{References}

[1] E. Karaharju and A. Hakkiluoto, "Strangulation of small intestine in an opening of the broad ligament," International Surgery, vol. 60, no. 8, p. 430, 1975.

[2] M. K. Aas-Eng, A. Langebrekke, M. Lieng, and E. Qvigstad, "Management of broad ligament defects and herniation of colon," Journal of Minimally Invasive Gynecology, vol. 24, no. 5, pp. 713-714, 2017.

[3] Y. Rohatgi and A. Joshi, "Broad ligament hernia: rare cause of intestinal obstruction-laparoscopic management," The Indian Journal of Surgery, vol. 27, 2020.

[4] N. L. Simstein, "Internal herniation through a defect in the broad ligament," The American Surgeon, vol. 53, no. 5, pp. 258-259, 1987.

[5] W. Marraoui, V. Petitcolin, S. Bros, K. Slim, J. M. Garcier, and D. Da Ines, "Internal hernia of the broad ligament: CT diagnosis for laparoscopic management," Diagnostic and Interventional Imaging, vol. 93, no. 7-8, pp. 621-624, 2012.

[6] Y. Hashimoto, T. Kanda, T. Chida, and K. Suda, "Recurrence hernia in the broad ligament of the uterus: a case report," Surgical Case Reports, vol. 6, no. 1, p. 288, 2020.

[7] T. Khetan, A. Hussain, I. Al-Shoek, and S. El-Hasani, "Laparoscopic management of strangulated broad ligament hernia," Hospital Practices and Research, vol. 3, no. 3, pp. 104-106, 2018.

[8] H. Takeyama, Y. Kogita, T. Nishigaki et al., "Broad ligament hernia successfully repaired by single-incision laparoscopy: a case report," Asian Journal of Endoscopic Surgery, vol. 11, no. 3, pp. 274-276, 2018.

[9] K. Toolabi, A. Zamanian, and R. Parsaei, "Bowel obstruction caused by broad ligament hernia successfully repaired by laparoscopy," Annals of the Royal College of Surgeons of England, vol. 100, no. 4, pp. e94-e96, 2018.

[10] J. H. Park, S. H. Kim, and Y. H. Cho, "Internal hernia through a defect in the broad ligament of uterus: laparoscopic management using a self-anchoring barbed suture," The Journal of Minimally Invasive Surgery, vol. 21, no. 3, pp. 130-132, 2018.
[11] E. Diémé, I. Sall, A. R. Ndiaye et al., "Internal hernia of broad ligament: a CT scan suspicion and laparoscopic treatment," The Journal of Pharmacy and Pharmacology, vol. 6, no. 2, pp. 157-160, 2018.

[12] D. Rajasekharan, D. Shanthakumar, S. Subbarayappa, and J. B. Nagaraja, "A rare case of small-bowel obstruction due to broad ligament herniation," Indian Journal of Colo-Rectal Surgery, vol. 1, no. 2, pp. 57-59, 2018.

[13] J. Zemour, X. Coueffe, and H. Fagot, "Herniation of the broad ligament... And the other side?," International Journal of Surgery Case Reports, vol. 65, pp. 354-357, 2019.

[14] M. G. Fernandes, A. R. Loureiro, M. J. Obrist, and C. Prudente, "Small bowel obstruction by broad ligament hernia: three case reports, management and outcomes," Acta Médica Portuguesa, vol. 32, no. 3, pp. 240-243, 2019.

[15] N. Reyes, L. E. Smith, and D. Bruce, "Strangulated internal hernia due to defect in broad ligament: a case report," Journal of Surgical Case Reports, vol. 2020, no. 11, 2020.

[16] N. Koizumi, Y. Ariyoshi, H. Fujiki, and C. Sakakura, "Needlescopic surgery for broad ligament hernia: a case report," Asian J Endosc Surg., vol. 13, no. 1, pp. 124-126, 2020.

[17] T. Sugishita, S. Kato, A. Ishikawa, H. Takahashi, and Y. Kawachi, "Less invasive treatment for broad ligament hernia: a case report," International Journal of Surgery Case Reports, vol. 73, pp. 172-175, 2020.

[18] R. Umer Harvitkar, B. Shelke, and A. Joshi, "Broad ligament hernia as a rare cause of acute small bowel obstruction: a wolf in sheep's clothing- a case report with review of the literature," Indian Journal of Case Reports, vol. 6, no. 12, pp. 691-693, 2020.

[19] N. Kaur, C. Bhatia, R. Kaushik, S. Bhardwaj, and S. Singh, "Broad ligament hernia- report of a case," Hellenic Journal of Surgery, vol. 92, no. 5-6, pp. 192-194, 2020.

[20] Á. I. Tirado-Peraza, E. González-Gutiérrez, A. MayagoitíaPonce, A. Zamudio-Martínez, and L. I. Ruiz-Guerrero, "Broad ligament hernia as an uncommon cause of intestinal obstruction," Remedy Publications LLC, vol. 6, p. 3036, 2021. 